
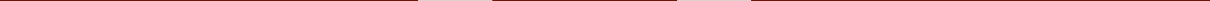


\title{
Methodological Challenges in 'Hostile' Environments of Preventive Archaeology
}

\author{
Predrag Novaković
}

DOI:10.17234/9789531757799.2

\author{
Department of Archaeology \\ University of Ljubljana \\ Aškerčeva 2 \\ SI-1000 Ljubljana, Slovenia \\ predrag.novakovic@ff.uni-lj.si
}

In the last three decades, one could witness the radical transformation of archaeology from mostly academic discipline to an applied research practice with a statutory role in spatial planning and development in the domain of heritage safeguarding. The very fact that today preventive archaeology ${ }^{1}$ comprises more than $90 \%$ of all archaeological research practices, makes the question of the context of preventive research in general and of archaeological methodology in particular extremely important.

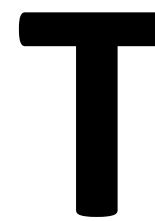

he increase of preventive or development-led archaeology was, indeed, of several orders of magnitude; the quantity of excavations alone is more than ten times greater than some thirty years ago. However, parallely increased also the 'openness' of (preventive) archaeology to a series of influential factors coming from outside the discipline and academia. The issues, such as funding, the scale of projects, time-planning, types of stakeholders involved etc. greatly differ compared to the archaeology in the academic domains. Indeed, these external factors may, and frequently do, act in the opposite way of the goals of the statutory aims of preventive archaeology, attempting to make it as cheaper and faster as possible. While this pressure had certain positive effects on archaeological practice in terms of better organization,

1 In this paper we use the tem preventive archaeology as a general term for all archaeological research activities in heritage safeguard- cost efficiency and increased social responsibility, and catalysed some important improvements in its performance, we still must not forget that what developers are de facto paying is a piece of land "freed of archaeological heritage" and not the best solution for the archaeological heritage. In this sense, it is logical to expect constant challenging not only of the individual archaeological preventive projects but the whole system of prevention and safeguarding of heritage as well. Willems and Brandt (2004: 9) pointed out the obvious fact that market principles can only be permitted if the quality of the necessary archaeological preventive research has been secured; otherwise commercial logic will prevail. That such pressure exists on higher governmental levels illustrate well recent attempts in the legislation in many European countries aimed at 'creating more friendly

ing. It is used instead of other freequent terms such as developmentled archaeology, rescue archaeology, conservation archaeology etc. 


\section{Theoretical model}

FIGURE 1. Theoretical model of archaeological methodology

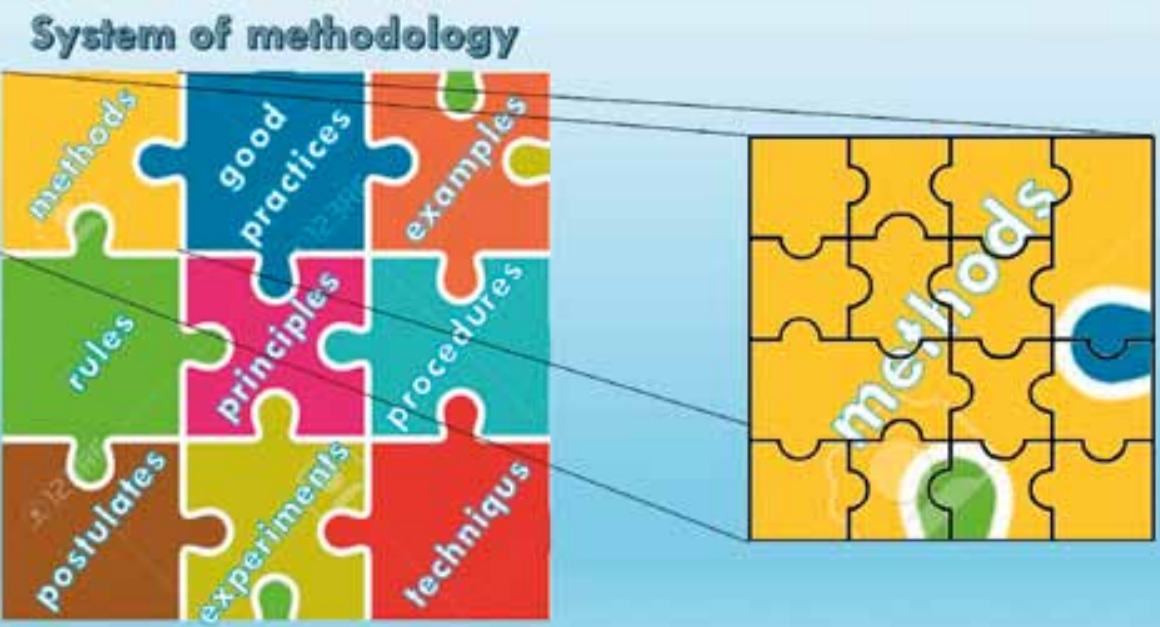

environment for the investors' (e.g. Slovenia: Novšak (2016), Italy: Guermandi (2016), Hungary: Czifra and Fabian (2016), Bozoki-Ernyey (2016), Romania: Simion (2016), Măgureanu and Măgureanu (2016), general situation: Demoule (2010). One could easily imagine an equation - more friendly the environment for the investors, more hostile for preventive archaeology.

The aim of this paper is not to discuss all aspects of hostile environments but, primarily, to reconsider the role of archaeological methodology in such a context. The legal, economic and social pressures posed on professionals in preventive archaeology (working in public or private institutions) have direct consequences also on the ways how research in day-to-day practice is performed and its results reported. While it is clear that archaeological discipline is constantly developing common methodology, and consequently also the standards and good practices of what is accepted as correct research methodology, in practical situations, most frequently in preventive archaeology, the idea of standards common with academic archaeology have been frequently challenged, or better to say 'readjusted' according to individual situations.

To start with, in Figs. 1 and 2 we have presented two models for archaeological methodology, one theoretical and the other in the applied situation (practice). In both contexts, we have considered a system of methodology as composed of interrelated subsets or domains: methods, rules, postulates, principles, experiments, techniques, procedures, examples and good practices. Each of these domains can be further broken down into its constituent elements.

Practical model (Fig. 2) illustrates the dialectic of theory and practice. Each research situation in practice is unique, has its own set of methods which at one hand draw its knowledge from the general system of archaeological methodology by selecting and readjusting elements of this system according to its particular needs and research questions, while, on the other hand, it is also shaped by the influences of a series of practical factors, conditions and circumstances in which the actual research is taking place. In this sense, preventive projects can be considered as typical contexts of archaeological research practice with specific external determinants having an influence on its methodology (Fig. 3).

At this point it is necessary first to answer one general question - is practice in preventive archaeology in terms of it research nature comparable to the academic research. Our answer is yes! The fundamental nature of research in both contexts, academic and preventive, is the same, as well as the methods applied. The evident differences in goals, social roles and practical circumstances are just elements in the dialectic of archaeological practice and should not be overestimated. However, in practice, the differences may have been perceived as constituents for 'two' archaeologies. Later, in this text, we have dealt in more detail with this issue. 
FIGURE 2. Mode of archaeological methodology in practice.

\section{Practical model}

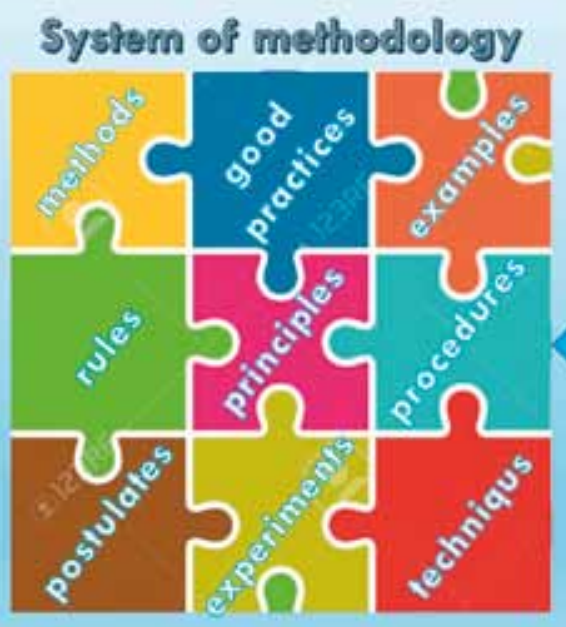

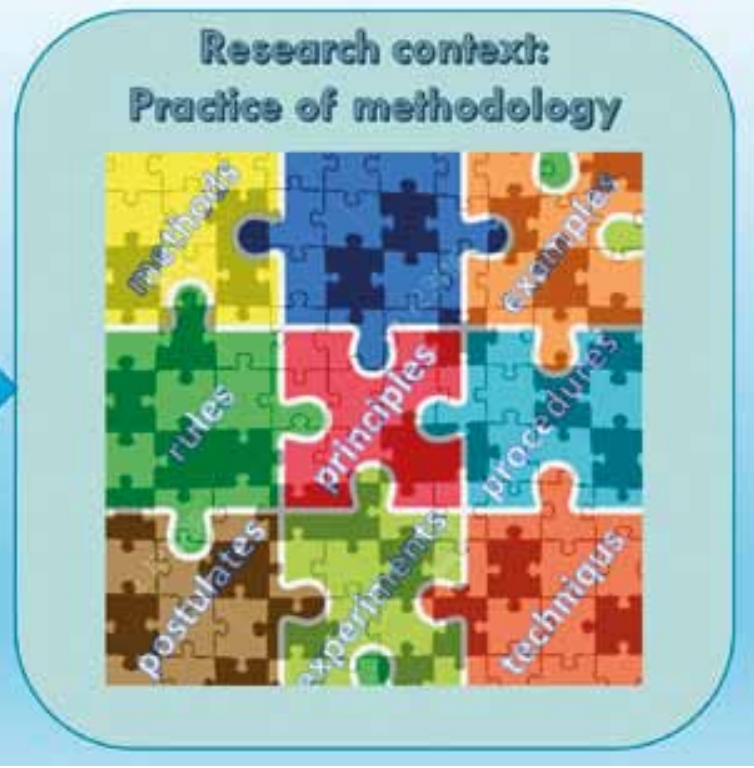

If we look at the goals of academic and preventive archaeology these differences may arise from different tasks ascribed to two archaeologies. Regardless of a number of different individual goals of academic archaeology, they all can be comprised under the task of 'producing new knowledge about the past', while the primary goal of preventive archaeology is normally considered under 'safeguarding the heritage'. Theoretically speaking, preventive archaeology is then seen as 'ap- plied' archaeology implemented in practical contexts. It is clear that we are talking here about two different primary social roles. However, these roles are not exclusive but interrelated. As academic archaeology assists in different ways to the safeguarding of heritage also the preventive archaeology produces new knowledge about the past.

\section{Context of research practice}

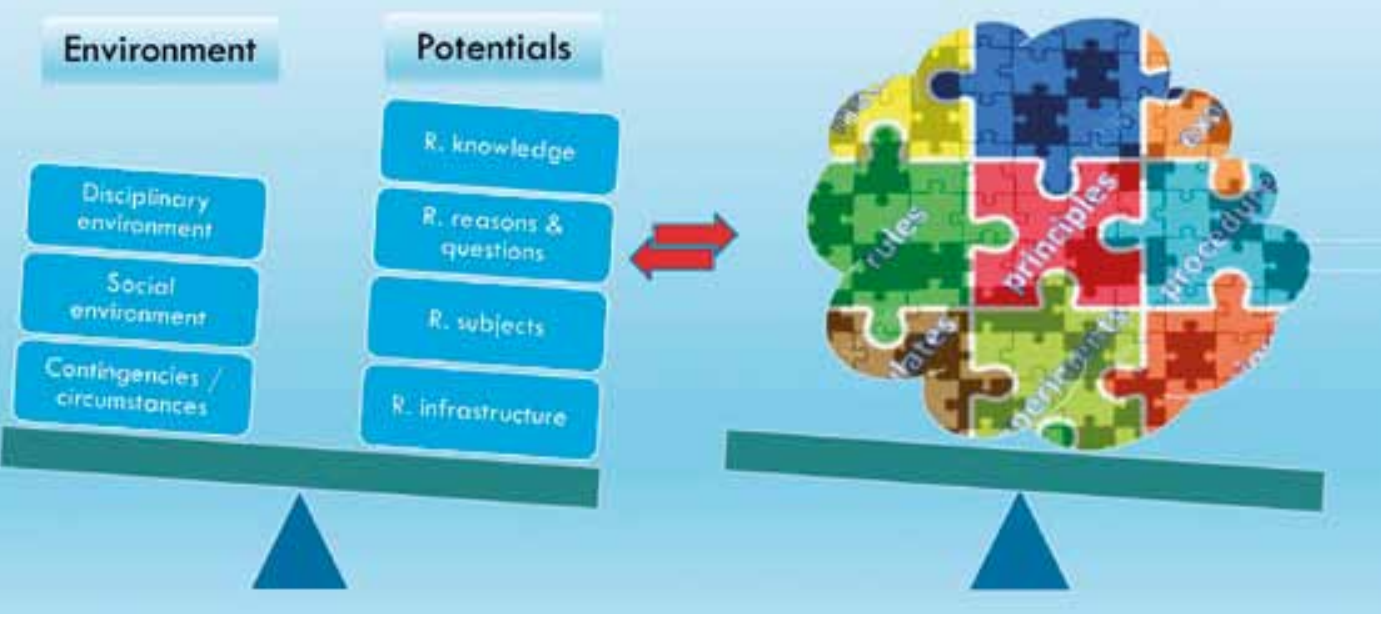


In Fig. 3 we have presented a model of research practice where the elements influencing the research methodology are grouped into two major groups: elements deriving from the environment in which research is taking place (disciplinary environment, wider social environment and local contingencies and circumstances) and potentials of archaeological discipline and practice (research knowledge, research reasons, questions, motives, subjects performing research and infrastructure available for research). Again, these two groups are not mutually exclusive; in fact, each individual element can be observed for its environment and potentials. If one would plot the elements of different projects, academic and preventive, according to the presented model, the existing differences between them would, again, not be so large to seriously deconstruct the disciplinary unity of archaeology.

However, in actual practice in many countries, this does not seem so obvious. Since the introduction of modern preventive archaeology based on the principles of the Convention from La Valletta (1992) one could, indeed, observe the widening gap between the academic and preventive archaeology, not only in practice but also in a number of conceptual issues. The situation can vary from one country to another. But accepting divergent development and doing nothing to abridge this gap poses great threats to the unity of discipline, and could easily challenge its relevance in all its social contexts. For this reason, it is important to reflect some major facts regarding the differences between the academic (purely research-oriented) archaeology and preventive archaeology (applied, heritage-oriented), and to reflect the methodology in both.

a) Differences in motives/reasons for research

In principle, academic archaeology is fully autonomous in selecting research topics and constructing its research agenda. Preventive archaeology has much more limited range in this domain. Here, the areas, types of sites and other archaeological phenomena to be researched are not selected in advance for archaeological research purposes but simply because certain areas containing archaeological evidence are threatened by different external factors, mostly by development. In terms of methodology, or better to say in terms of maintaining the correct level of its implementation, the reasons for research should not have any considerable effect.

b) Compared to the academic domains, preventive archaeology works in a much less control environment and conditions. Many external factors (e.g. funding, extent and duration of the projects, weather conditions, the subject of research etc.) can condition a great deal of the preventive research. Here it is of essential importance the system of funding. The truth is that the introduction of principle 'polluter pays' enabled considerable improvement in funding, and is directly responsible for the recent enlargement of preventive archaeology, but it also deserves some reflection regarding some negative practices. The principal question here is who estimates the costs of preventive projects and how they are estimated. In countries where a great deal of preventive archaeology, especially fieldwork and associated activities, is a matter of market competition, one could witness several negative outcomes. The most concerning is predatory pricing which mostly derives from the fact that the final price, and frequently also the initial estimates, are frequently set without full comprehension and consideration of the archaeological research requirements (and standards if they exist). The philosophy of market competition is based on assumption that the buyer will always weight the price and quality of the product he is buying, and the outcome should be the optimal solution for the buyer. But, such philosophy completely fails if the buyer is not interested in the product at all? As we have said before, the developers are not interested in the results of preventive research. Leaving to them to set the price they are willing to pay for 'emptying the land of heritage', without any regulations and mechanisms allowing authorised public (state, regional, local) bodies to secure a minimum of necessary funds based on expert estimates is bound to undermine the quality of research. Public bodies must have some statutory role for at least one simple reason - in all countries, the heritage is considered public good and the public, via its authorities, must have some power in protecting it. Otherwise, the environment for preventive research would soon turn into extremely hostile, and the consequences for the whole discipline of archaeology would soon become catastrophic. In such a hostile environment the implementation of methodology would be among the first to suffer serious setbacks.

c) While the academic archaeology, by its virtue, can and should experiment and test new methods and techniques, preventive archaeology, in practice, tends to limit the methodological arsenal to the set of 'routines' to perform research as efficiently as possible according to the 'agreed' or 'standard' level of practice. This, of course, does not mean that there are no methodological innovations in preventive archaeology, the pressures of the business context in its own ways catalyses the progress, but the motives for development of new methods may considerably vary between the academic and preventive archaeology. In simple words, while in practice the academic archaeology would invent new methods 
or improve the existing ones to enlarge the knowledge and to provide new ways of getting the knowledge, the preventive archaeology would seek for methods to get such knowledge faster and more efficiently. But do we speak of the same 'knowledge'? In theory yes, but not necessarily in practice. While academic archaeology is, in principle, unlimited in seeking new knowledge, in the everyday practice of preventive archaeology the "knowledge' takes on additional meanings - the one associated with the knowledge of cultural resource protection and management systems which are frequently based on a set of regulations.

d) Decisions derived from the results of preventive research have normally much greater weight and longerlasting implications, especially from the point of view of heritage protection. It is nothing new to say that the responsibilities of the academic archaeology are primarily within the disciplinary and scientific contexts while the professionals in preventive archaeology have much larger responsibilities in wider social, economic and community contexts. Of course, they are not excluded from the responsibilities in the disciplinary context. When speaking of responsibilities in preventive archaeology we must be aware of the fact that there are at least two different positions in the preventive archaeology with different responsibilities. The first group are those professionals who decide whether the preventive projects are necessary, they normally prescribe its size, basic methods, and they may also decide on different stages of preventive research, and frequently also how to proceed with heritage safeguarding in the future. The other group are professionals who actually implement archaeological research based on such prescriptions. The monitoring of the research and evaluation of the results is normally the task of the professionals from the first group.

In practice, both groups can be exposed to various external pressures. In practice, these pressures very much depend on how in general the development, real estate and building activities are regulated and environmental protection respected. In countries with a lot of illegal constructions, one could hardly expect positive public culture towards heritage. There the pressures may come from illegal lobbying and political pressure to 'make things go', and come very close to corruptive practices.

These four points, though not completely covering the issue of methodology in the context of the hostile environment in preventive archaeology, nevertheless, give clear orientation for the discussion about the actual challenges in this domain. To this end, we would further focus our paper on the following issues we find essential for 'safeguarding' the methodology in the future:

a) The relationship between two archaeological 'professional cultures' from the perspective of methodology application and development

b) Quality of research and presentation of results

c) 'Big data' problem
FIGURE 4. Diagram of friendly and hostile environments in archaeology

\section{Two environments: friendly and hostile}

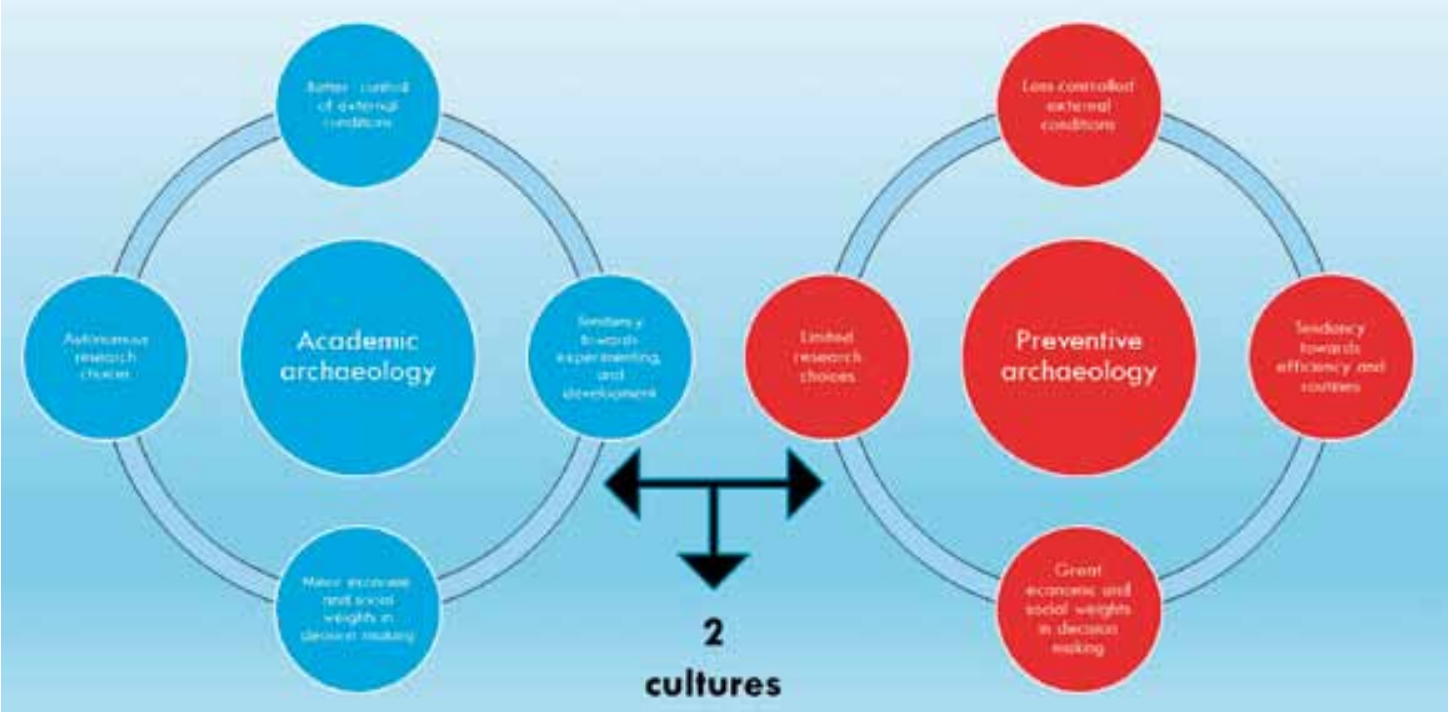


Fig. 4 just illustrates the well-known fact, that in spite of a number of external factors influencing the nature, content and size of academic archaeology, it, generally, operates in an environments which are far less 'hostile' (i.e. much fewer external criticism of relevance and needs for such research) than in the case of preventive archaeology. Again, we do not insist on a strict division between the two environments, what we would like to illustrate here is the distinction between the two extreme situations.

\section{Two archaeological professional 'cultures'}

Much about this has already been said by other authors (e.g. Bradley 2006) who points to the fact that this divide to a great extent originates from self-perception of the professionals in archaeology. We find this observation very important; what follows from it is that archaeology (and archaeologists) are seen as much more homogenous by the non-expert public. Most of the people simply do not distinguish between the 'two' archaeologies and very frequently project stereotypes, criticism and simplifications on whole archaeology, regardless whether it is academic or preventive. This is even more accentuated in the 'hostile' environments where archaeology (preventive) is considered as one of the obstacles to development.

Bradley (2006: 6) warns that the research aspect is becoming marginalized in the preventive archaeology since major regulative frameworks and documents give priority to conservation agenda. Similarly argued Carver (1996) who sees research and the creation of knowledge being replaced by the management of heritage assets - research of unknown gave a way of research of known. Fitzpatrick (2012: 150) notices that practicebased research is frequently perceived as in some way inherently inferior to academic research', and that exists a belief which distinguishes between 'thinkers' and 'doers' of archaeology and that research is commonly seen as a creative process while commercially organized research is mundane. Everill (2009) also notes the 'invisibility' of researchers in the contexts of preventive archaeology while in the academic domain the visibility of very strong. And, last but not least, many argue that the speed and number of development-led projects cause a decrease in the quality of work.

One of the major reasons for the emergence of two archaeological professional cultures are definitely different business conditions and circumstances. While the competition for jobs and projects in the academic ar- chaeology is mostly based on evaluation by peers (i.e other academics), this is definitely not the case in preventive archaeology, especially in those countries which introduced a 'commercial' status of the preventive research as marketable services. There the competition is based almost entirely on commercial factors. This is also the case when investors are public bodies or agencies; the EU directives regulating public procurement order them to select the bidders which offered the lowest price. This, of course, sheds a different light on the issues of quality and its control. It is not a surprise that in countries with highly 'commercialised' archaeology the differences between the two cultures are much more enhanced (e.g. in the UK, Ireland, Italy). In spite of the fact that the principle product of both, academic and preventive archaeology - new archaeological knowledge produced and cultural heritage enriched (and/ or saved in preventive research) - the quality of work seem to be measured differently and have different effects. Since we would not go into more details here it suffices to point to the cases where preventive archaeology is still the domain of public authorities, and where the practices of quality control seem closer to those in the academic world (e.g. in France or Germany). In the case of 'commercial' preventive archaeology, quality control contains several other aspects than just the archaeological contents or results, which are measured by non-academic or non-disciplinary criteria.

Bradley (2006) points to a major problem of the relationships between the two cultures - their lack of communication and understanding which is the major reason for mutual criticisms. While the academic archaeology questions the quality of research (i.e. its reductionism), recording and publication in preventive archaeology, and less-than-adequate contribution to the general knowledge of the past and heritage, while on the other side the preventive archaeology accentuates its social relevance and its role in sustainable development strategies, high skills learned in research practice, deeper engagement with public etc. And, least but not last, its vast contribution in the domain of new discoveries, the quantity of data obtained through preventive greatly exceeds those from the academic archaeology. However, the academic archaeology still to a great deal insists on the scholarly image of archaeology. Carver (1996) sees this as a structural difference between creating and safeguarding of heritage (cultural resource management) and production of new knowledge per se (academic scholarship). On the other hand, Rajkovača (2017: 29) argues that the challenges in the system of cultural resource management and academia appear to be the same. 
FIGURE 5. Characteristics of friendly and hostile environments for archaeological research.

\section{Divergent trends in preventive archaeology}

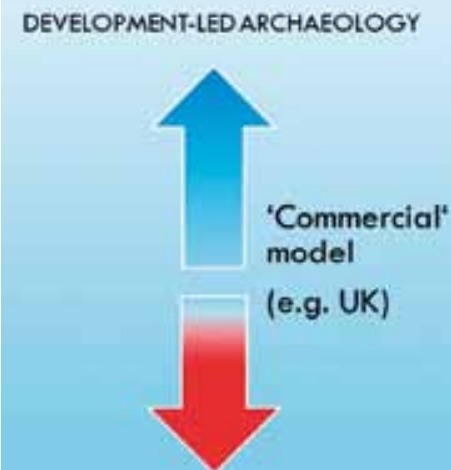

ACADEMIC ARCHAEOLOGY
WORK

- Age difference

- Working environment

- Employment stability

- Working mobility

- Promotion potential

- Social networks

\section{ARCHAEOLOGY}

- Publication

Communication

Creativeness
DEVEIOPMENT-LED ARCHAEOLOGY

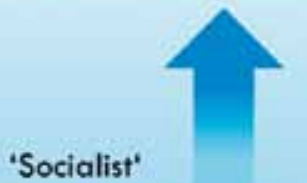

model

(e.g. France)

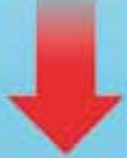

ACADEMIC ARCHAEOLOGY
This mutual criticism contributes in its own way to a 'hostile' environment for archaeology. If preventive archaeology becomes increasingly separated from academic archaeology it also becomes more exposed to the criticisms from outside the discipline, especially from the stakeholders who can have direct benefits from making it weaker. In such a scenario where heritage safeguarding is losing its powers and statutary roles, there is a great responsibility also on the academic archaeology to actively intervene to remediate the situation. Though the academics and their institutions are frequently not the stakeholders directly involved in the processes of negotiating the individual preventive research projects, they can contribute in a different way, by being actively involved in the creation of research standards and quality control systems in archaeology. In other words, if a preventive research project should not methodologically differ from a standard academic research project, then why it is not evaluated as such. The fact is that majority of preventive field projects end with reports, which are in many cases more technical and descriptive than scientific and interpretative in their nature. If the data presented in these reports are not fully scientifically evaluated and reports themselves subjected to peer reviewing the potential of the preventive research far from being optimally exploited.

Criticising exclusively the professionals in preventive archaeology for poorer quality of reporting and otherwise presenting their work would be a great error. It is the system of heritage safeguarding which is not recognizing the full scientific evaluation of data as inseparable part of preventive research and is not providing adequate means for such an evaluation. This is especially the case in highly commercialized national preventive archaeologies, where legislation, describing the concept of 'preservation by record', insists on dividing the safeguarding of heritage into a series of individual activities, mostly those 'technical' in nature (e.g. excavations and primary processing of finds and documentation), which are compulsory for funding by developers. More complete scientific expertise is mostly left out of the funding scheme as if the excavations and removal of the 'sites' to museums and record archives make the safeguarding of heritage 'accomplished'.

The domain of scientific evaluation seems to me the most authentic field for fruitful cooperation between the professionals from academic and preventive worlds. Provided that the funds for are secured this cooperation can be implemented in all aspects and stages of the preventive projects, from the preparation of projects, counselling on certain archaeological issues, monitoring, active engagement in post-excavation analyses, peer reviewing etc. What it takes is to create a system where such cooperation becomes a routine. The benefits would be great for both sides, the academics would get far more familiar with many aspects of doing business in archaeology, organization, logistics, would gain experiences of working in very demanding and chal- 
lenging conditions, they would extend their professional networks, and they would also be in more direct touch with finds and sites and other phenomena they are professionally interested in. And, why not, they could also upgrade the university curricula with topics relevant for professional careers in preventive archaeology. If anything, then it is the development of new or faster and improved techniques of field methods which is taking place primarily in preventive archaeology.

Of course, it is easy to put such proposal on paper, but the truth is that if look more closely on the organization and practice of preventive archaeology in different countries in Europe, one can find a number of cases of good cooperation between these two professional groups. Most practitioners in preventive archaeology operate on local or regional levels having so less opportunities for international cooperation than the academic archaeology and also for being informed about the practices and achievements abroad. Academic networks and means for disseminating information can be far more easily mobilised than asking a number of small private enterprises to look for potential partners outside their country. This is also very frequently the case where preventive research is done by public institutions. These institutions, national or regional, effectively implement preventive projects with their local staff who could easily spend decades of their career working in one region. While this may make them excellent connoisseurs of the archaeological situation in their regions, it does not make them equally good researchers, especially if their access to information abroad is limited.

There is also one domain worth exploring that of the decisions made upon the results of research. Here, the preventive archaeology, in all stages of the research process, has a much greater responsibility than the academic one, and the decisions made are much more open to criticism by many parties. Research aimed at creating a dataset of archaeological potential of the individual area or site to support further decisions on size and type of development to be eventually permitted has a set of important short- and long-term consequences. And these consequences are felt in both, in the ways how archaeological heritage is safeguarded and in archaeological knowledge in general. In fact, this can be observed as one of the most critical points in implementing a suitable methodology.

\section{Quality of research and presentation of results}

The effects of the hostile environment are probably the best felt in the domain of quality of research and presentation of the results. Though, in theory, there should be no difference in terms of methods and standards between the two contexts, academic and preventive, in practice, this is not so much the case. It would be too simple and erroneous, to say that the reason for this is in the limited scope of the preventive research - to "save the archaeology by the record" while academic archaeology pursues 'deeper' insights and research which goes beyond the safeguarding of heritage.

Quality of research is directly associated with the methodology planned and implemented in practical situations. In both contexts, academic and preventive, every single project is unique and unrepeatable enterprise. Official standards and guidelines, if they exist, as well as cases of good practice must be always interpreted in the context of the individual project. This does not mean, that the standards can be ignored, indeed they have to be strictly referred to in all phases of the projects, and their requirements carefully studied and reflected against the goals of the project. While this may not be so difficult in the academic research contexts, it may prove more challenging it the preventive one. By challenges, I do not think only of pressures on preventive works to be as efficient and cheap as possible, but also on another fact deriving from the so-called 'conveyer belt' archaeology where standards and guidelines are often perceived as compulsory 'manuals of modus operandi' which need to be followed. Subduing to such philosophy denies the most essential characteristic of archaeological projects, they are all highly creative enterprises. Creativity is essential to any research, and taking it away from a great number of archaeological projects (let us not forget that more than $90 \%$ of the projects are preventive) is a great mistake, and, literally, the end of archaeology as we know it.

It is my opinion that it would be irresponsible from academic archaeology not to be involved in the safeguarding of heritage, and to pursue academic agenda alone. The quantity of new data coming from the preventive research exceeds for several order of magnitude the quantity deriving from the academic archaeology. One could say that in practice the data from preventive research may not be as structured and detailed as the data from academic research and that its quality could not always match the level of the quality in academic research. But, if there is a domain for good and logical cooperation between preventive and academic 
archaeology, then there is quality control. In the previous chapter, we have already proposed some steps for improving the quality of reporting by involving academic archaeologists into the processes of evaluation and peer-reviewing of the reports of the results from preventive research. This would not only increase the quality of reports themselves but also help both sides, preventive and academic, to understand the conditions and circumstances of the other. The other possible step towards the improvement of the quality is also involving academics into monitoring of research work, or at least of those parts for which they are competent. The benefits of such cooperation are definitely mutual. The skills, experiences and knowledge required for running large-scale projects are definitely much more developed among the field professionals in preventive archaeology. They have probably researched far more different sites, encountered far more complicated situations and worked in much more challenging conditions than academic archaeologists. Moreover, whoever had directed preventive project had to take into account different agendas, academic challenges had to be considered together with safeguarding priorities and rules, and business requirements. In this context, the issue of research quality has to be equally considered also outside the more narrow domain of academic standards.

In practice, in the last twenty or so years, as a major tool for ensuring the quality of research in archaeology in a number of European countries became standards. Though the standards are not the only tool in the system of quality securing and management, one should also think of other types of regulations, good practices, recommendations, ethic codes, tutorials etc., in practice the standards are probably the most important elements of such system. However, there are many types of standards, and not all 'standards' can be considered as equally important. In the first place, they can be distinguished according to their issuer, or better to say, according to the principle intention of the issuing body. We will best illustrate this with the cases of the Dutch archaeological standards (Willems and Brandt 2004) and the standards issued by the Chartered Institute for Archaeologists in the UK (CifA). The Dutch standards were issued by the public body responsible for heritage protection within the Dutch legal system), while the CIFA standards were issued by an organization of the professionals, which is essentially an NGO aimed in the first place at protecting the professional archaeology (and its professionals). They both have an important role in their respective countries, but when observing legal powers, the standards issued by public or even governmental bodies have much greater powers. However, also the powers of CIFA should not be ignored. CIFA, as leading professional body in the UK archaeology, represents archaeologists to the government, policy makers and industry. In this sense, CIFA directly acts towards mitigating the conditions of hostile environments. The Dutch-type of standards, which are more frequently oriented towards 'how the archaeological heritage is researched in the correct (prescribed) way' may also have important mitigating effects, but they not directly deal with professionals in archaeology. The other distinction between these two types of standards is, that some Dutch-type forms of 'standards' exist in a number of European countries, while CIFA-type standards can be found mostly in countries with larger numbers of professionals in archaeology working in 'commercial' conditions. Smaller countries, with only a few hundreds of professionals, have rarely if at all, professional bodies similar to CIFA. In fact, their role is assumed, but very partially, by the professional societies, especially in the former Eastern European countries (e.g. national societies of archaeologists).

The standards I would focus on in my text are primarily those issued by public (or governmental) bodies aimed at ensuring the quality of heritage protection. By saying this. I do not want to diminish the importance of professional ('guild') bodies and their standards and/or their ethic codes, but they gain in importance mostly in larger systems of professional archaeology, especially in 'commercial' environments where situations considerably varies from one country to another. Moreover, also the standard issued by public bodies responsible for heritage protection may considerably vary, some of them try to cover all major aspects of archaeological works, while others are dedicated to individual aspects only (e.g. data archiving, data classification, storage etc.).

However, not all texts, acts, and documents issued for the protection of heritage can be standards proper. Governmental acts (laws) are documents which normally define concepts and objects heritage, its legal status and system of their protection, stakeholders in heritage protection process and liable practices of protection. In other words, such documents normally define the general basis for the practice of heritage protection. More detailed regulations and standards proper normally appear at lower levels of legislation and regulation, and their status may also depend on the legal status of the issuing body. It is beyond the scope of this paper to discuss archaeological standards in all European countries. Indeed, the situation varies considerably, from countries with standards issued by their ministries responsible for archaeological heritage (smaller number of countries) to 
countries with no such standards where their role is assumed by some regulations which may cover only some aspects of the archaeological work in heritage protection, and are not as detailed as one would expect from standards. It is interesting to note here, that in comparison with the archaeology and heritage protection in the USA, which practices highly commercialized system, the standards in the European countries are much less present and developed.

Why we find standards so important? I would not go into the obvious: standards are making work more unified, ease the communication and understanding of research activities within the professional community, make the results more widely comprehensible etc., my point here is that standards protect archaeological professionals at all levels of the archaeological research process, and especially in the hostile environments. Of course, not all standards have the same protecting powers, but the standards issued by major public bodies definitely have them. And, here again, there is a place for fruitful cooperation of professionals from preventive and academic archaeology.

The Dutch standards are a good example of such cooperation. There, in 1999, a special national committee was established composed of all major expert parties involved in heritage protection (and preventive archaeology): universities, private enterprises, local, regional and national governments, the Dutch Association of Archaeologists, representatives of the developers (Willems and Brandt, 2004: 10, see also Appendix VI). Such a wide representation and exhaustive discussion was essential for successful adoption and implementation of standards. A similar process can be seen in Slovenia. There, the new Cultural Heritage Protection Act (2008) required from the Ministry of Culture also the adoption of the Regulations for Archaeological Research (Pravilnik o arheoloških raziskavah 2013), which were adopted in 2013 and in its appendices contained standards for all major aspects of archaeological research, from types of fieldwork allowed, compulsory forms and contents of records etc. to archiving of the results and final deposition of documentation and finds in museums. Special committee appointed by the Minister of Culture, composed of experts coming from heritage protection institutes, research institutes, university museums, and experts from the ministry itself, worked on regulations and standards for about 2 years. The standards alone were created on the basis of a special study commissioned by the Ministry of Culture already in 2006 (Novaković et. al. 2007).
The adoption of standards is an important step but it is not enough. The truth is, that, for example in Slovenia, the situation in preventive archaeology considerably improved, but crucial is the implementation. Without proper mechanisms and tools enabling efficient implementation, the standards may easily be ignored. Here again, we point to hostile environments where the implementation of standards is mostly challenged (e.g. as 'bureaucratic', non-practical, difficult to respect, stateenforced regulations etc.). It is also true that implementation and respect of standards has also much to do with the general culture of respecting the state laws and regulations, appreciating the heritage and environmental issues. I do not intend to go into this in more details but just to recommend careful consideration of all aspects which may hinder the implementation of standards. Better some standards than none.

\section{'Big data'}

The concept of Big Data (re)emmerged in the field of the digital and is associated with a rapid increase of computers ability to accumulate and process quantities of data much larger than ever before. Archaeology has already passed the threshold of 'Big Data' without being fully aware of this passage. Not so much internally as a discipline but externally, as a practice done in environments and contexts which are using big data. What changed for archaeology, in the first place, are the environments and social and economic contexts and activities which increasingly take advantage of Big Data ideas, solutions and technology, and which directly or indirectly exercise influence on archaeology and its practice. ${ }^{1}$

Much of this paper is dealing with the relevance of archaeology, and its relevance can be again at stake if archaeology would ignore or delay in accepting the challenges provided by Big Data. There is much more to Big Data than just large datasets and technology to effectively manipulate with them. It is true that the initial definitions of Big Data spoke of large scales and quantities of data whose processing exceeded the capacities of 'normal' computers, but the potential of Big Data was soon revealed in dimensions and perspectives hard to predict some 10 years ago. Some scholars (e.g. MayerSchönberg and Cukier 2013) speak of a genuine revolu-

1 At the moment, the best example of Big Data associated with archaeology is the project Europeana (https://pro.europeana.eu/ our-mission). The project is very ambitious and includes all types of cultural heritage. It started as a platform for communication between libraries but it soon grew into more ambitious project - general information platform (and archive) for European cultural heritage open to all citizens and creative industries. 
tion affecting not only the way how we treat data but also how we understand and organize our society.

Presenting and explaining Big Data concept is beyond the scope of this paper and we will just remind on some of its major aspects which we find especially relevant for archaeology. Mayer-Schönberg and Cukier (2013: 13-15) speak of three major shifts associated with Big Data. In the first place, there is a shift from sampling small (and as representative as possible) samples to sampling all. All users of Facebook or Amazon are taken as a sample, their every individual click or word or number they type, or even time spent on a certain web page are recorded and can act as a sample for analysing their behaviour. Then there is a shift from exactitude of data on smaller scales of observation towards their messiness on larger scales which, instead, enables insights at macro levels. And, finally, there is a shift from searching principal causality within data towards revealing correlations, sometimes very unexpected correlations. The correlations may not tell us precisely why something is happening, but they can alert us that something is happening (Mayer-Schönberg and Cukier 2013: 14). In this sense new, sometimes completely unexpected patterns and correlations may be revealed. This, in turn, opens the question whether narrowing down our research to test exact and clear hypotheses is fruitful approach; the common phrase is 'Big Data can be let to speak for itself'.

Current definitions of Big Data frequently stress 3Vs when describing its nature - Volume, Variety and Velocity. Some (eg. Harwitz et. al. 2013) add another 2Vs to it - Veracity and Value. Each of the individual Vs brings major changes. Today volumes of a number of datasets may exceed petabytes or even hexabytes (e.g. Microsft Academic has a dataset nearly 18 million publications by nearly 212 million authors, Google Books are nearly at 30 million publications) and their processing and services require computing power not of a single (super) computers but of computer grids and networks. The level of the velocity of data gathering is another phenomena not experienced some ten years ago. Today, almost unimaginably large amounts of data from various social networks, sensors, cameras etc. can be collected and shipped to servers in a blink of an eye. ${ }^{2}$ Dealing with such velocity obviously requires a completely different approach to data and what can be done with it.

Variety deals with structuration of data and datasets. In traditional data analyses, some kind of the structuration of data is normally the first step to be done, but it is estimated that after decades of digital data collect-

2 Facebook generates som 250 million posts per hour. ing and analysing only $30 \%$ of datasets are structured, the rest is simply messy, and can be extremely messy. Since it is difficult to apply rules on an unstructured data this, again, requires different approach and tools to deal with. The importance of the last 2 Vs: veracity (i.e. reliability or trustworthiness or accurability of data) and value (adding new values based on data) only increase through time and with accumulation of more and more data, and they also require suitable tools for filtering out the anomalies, inaccuracies etc. or new predicting tools.

Many practitioners in archaeology would agree that what is the most obvious aspect of Big Data experienced in the discipline is the increasing volume of data. This increase is directly associated with the application of digital technologies in archaeological research. Since around the year of 2000 when digital cameras were introduced the number of photos taken at excavations increase enormously, as also various measurements taken by surveying instruments, and millions of various datasets were created in digital forms. This, of course, speeded up the process of recording, made it more accurately, increased the structuration and standardization of data and eased data processing. While this seemed at the first sight a great relief for those working in the field, the price was paid in later stages of archaeological work. If one would stick to the conventional approach to data he would spend much more time sorting, classifying, filtering, and discarding redundant data as ever before. There was a clear negative correlation - more data is taken in automatic modes and time saved, more time is spent making it understandable let alone usable in later stages. To illustrate this phenomenon it is enough to look at how much data was collected and how much of it was published, and how much work on data is distributed along this axis. It is becoming clear that if we would like to successfully fight the incoming 'data flood' that not only new and faster tools are needed, but much more than that - new considerations about data.

The issue of velocity brought by Big Data technologies may at the moment seem not that relevant for archaeology. Today we are rarely using if at all, sensorial technologies to record different archaeological activities in real time. We simply do not have such needs yet. But, if we look in wider context and include heritage, perceptions of archaeology and past, and similar notions, then the importance of velocity becomes soon very important. It is possible to imagine a large number of things where different kinds of sensor-collected data can be very useful, for example, one could get a much better insight about ideas, expectations and impact on 


\section{DATA NEVER SLEEPS 3.0}

How much data is generated every minute?
Daca is berg creserd at the time without us even nobing it. Much of what we do every day now happens in the diceal reaim, leaving an

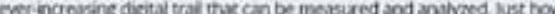

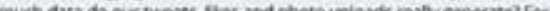

FIGURE 6. Data

generated per

minute in 2018.

Source: https://

wersm.com/

how-much-data-is-

generated-every-

minute-on-social-

media/

\section{UBER \\ Skype \\ $110,040-694$}

Buzriecel

USERS VIEW

:391, $1 \frac{\pi}{10}(1)$ VIDE0:

CALLS
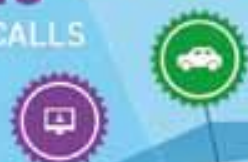

(4)

SNAPCHAT

284,722

sond

Users Tinder

590,278

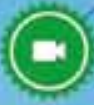

VINE USERS

$1,041,666$

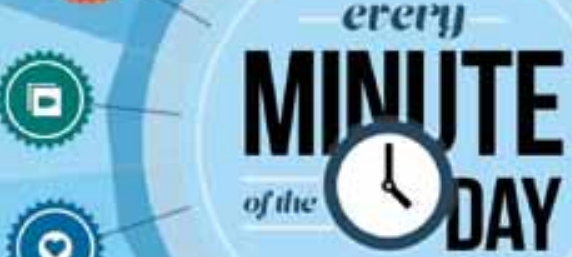

VIDEOS

\section{1,310}

1.310

\section{Facelbook}

USERS LIKE

\section{$4,166,667$}

Posts - 3:17,222
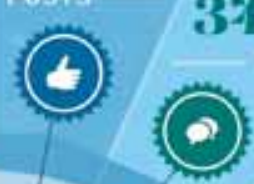

YOUTUBE $3(1)(1)$ hours

[D]

OF NEWYYIDEO

Instagืเam

\section{(10)}

$1,736,111$

4) PINTEREST

USERS PIN -

9.722 IMAGES

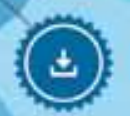

(๑) APPLE USERS

Nerlix

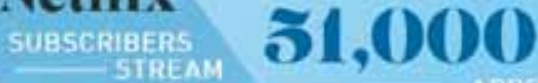

\section{(23)}

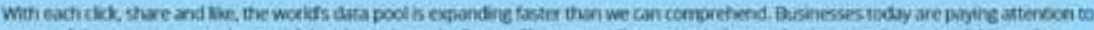

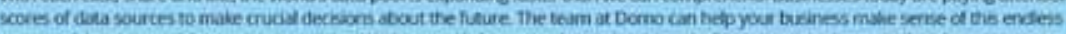

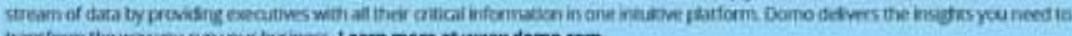
trintform the woy you rin your beciness Learn more at wwwedoma.com.

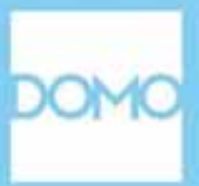


the behaviour of visitors, internet users and many other different populations. For many years large supermarkets and malls arrange their shelves and products according to the behaviorial patterns of different groups of customers in order to keep them as long as possible in their stores and boost impulse buying. One museum display or exhibition is not that far away. On the other hand, one can look at 'likes' and 'dislikes' at Facebook associated with some archaeological issues, and immediately act to decrease 'dislikes'. For example, if in media there are frequent news or opinions about excavations in town centres which are causing problems for traffic, local inhabitants, commuters etc., generally depicting archaeology as obstacle or unnecessary spending of money, the time to launch positive and better conceived online campaign is during the excavations and not months after they have been completed.

Variety of data is a long-standing problem in archaeology. The answer to this were great efforts to structure data in several, but still not many, standardized categories (morphological or functional types, chronological sequences, stratigraphic contexts, and other units of observation or categorization). In this way, data was collected and processed in ways shared by professionals in archaeology, as well as their results. But, as every practitioner in archaeology knows from its own experiences, the data is not that easily accommodated to 'default' categories, there are still many 'transitional', 'anomalous' and idiosyncratic forms which in many cases required their own individual 'category'. The other problem is more of epistemological nature. If one defines standard categories in advance (or just follow the prescribed standards), then it is very likely that the data will be 'normalized' in order to fit well in those categories.
This may prove more efficient and coherent but there is also a great chance of loosing or ignoring 'strange' data. Equally goes when one looked for the patterns in data. If one would focus on patterns for which he knows major determinants, he would limit his observation to proving or disproving these patterns, but he would also limit the potential of revealing other, not expected patterns.

Archaeology has very ambitious goals - to discover and interpret as many as possible aspects and phenomena of human life and activities in the past in every corner of our world and to assist with its knowledge in heritage protection, presentation and management in our societies. From this, it is clear that archaeology is constantly expanding its field of expertise and research, together with its ability to deal with the increasing quantity of data. But it is not the sheer quantity of data which requires reconsideration of data management in archaeology, it is the structure of data which is actually causing greater problems. Seeing the increased quantity as the only major problem would lead us to the 'conveyer belt philosophy', in this sense it would suffice to develop appropriately faster and more efficient ways for data retrieval, storage and processing. This is a classical positivist view from which stems that more data means more accurate and better answers. But this ignores basic dialectic of science and research where theory, practice and environment in which science is practised, contrasted to each other, resulting in new ideas and concepts in all three fields. In other words, new discoveries or new types of research always open the question of whether actual theories or interpretations (and their basic assumptions) can accommodate them or they need to be changed and improved.

\section{Google Books Ngram Viewer}

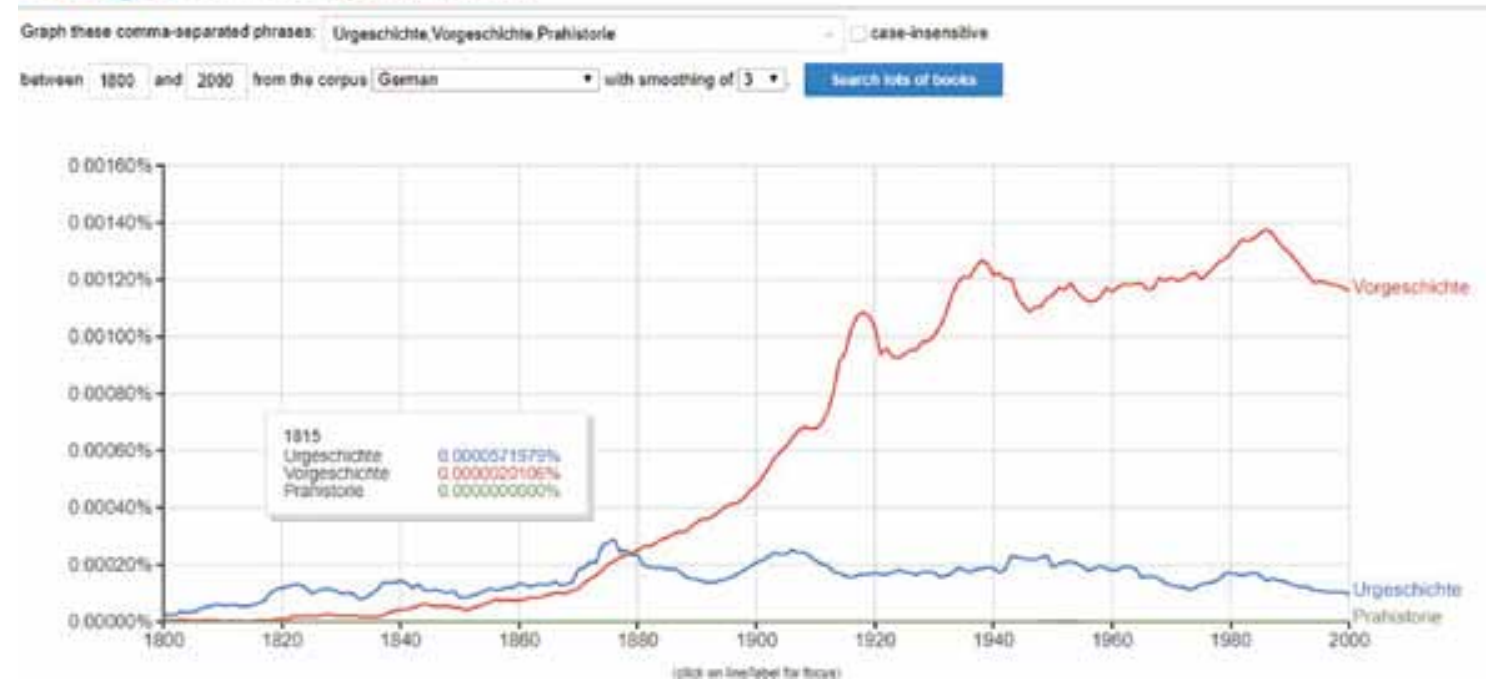

FIGURE 7. Ngram's relative frequency (in \%) of words 'Urgeschichte', 'Vorgeschichte' and 'Prahistorie' in German texts stored in Google books. 
It is clear that archaeology should very soon introduce Big Data concepts and tools in its methodology. It is expected that this will be first done in the academic domains which have more space and time for testing. It is hard to predict in which areas concepts of Big data in archaeology will prove successful. One possibility is using existing Big Data services such as Google Books and their highly attractive ngrams which compute the frequency of specific words in their large book repository spanning from the last decades of the 19th century onwards. This possibility opened completely new insights into cultural patterns of modern society and is responsible for the new term 'culturomics' - a special type of computational lexicology (Aiden and Michel 2013).

To demonstrate the potential of ngrams with one simple case, the frequency of words 'Urgeschichte', 'Vorgsechichte' and 'Prahistorie' in German books recorded by Google Books.

From the graph above it is very clear that the word 'Vorgeschichte' appeared later than 'Urgeschichte' and become more frequent than 'Urgeschichte' at around 1880 and only increased through time. What does this mean? At this point it would be probably premature to jump to conclusions, e.g. that 'Vorgeschichte' became more frequent as archaeology became more culturalhistorical oriented in German-publishing world, but having ngrams gives us the opportunity to research this change in a reasonable amount of time, and to test this hypothesis within a context of German language, archaeology and culture. However, what is important to note here is that in spite of a number of inconsistencies of Google Books, possible errors during the datafication process (e.g. OCR of scanned texts), non fully representative samples of German texts etc., the result of ngram would not be much different even if all the errors would be corrected. Big data simply does not have to be full exact.

There are also many other existing Big Data service the archaeology can take advantage of, e.g. in environmental monitoring, people's behaviorial monitoring (on-line and off-line), monitoring of public opinion etc. And then there are also tools for dealing with archaeological Big Data (data produced by archaeology). In this domain, we expect first the adoption of tools for dealing with unstructured or poorly structured data, especially the adoption of different nonrelational (nonSQL) databases which offer much greater flexibility and scalability than traditional SQL databases. Another field where we expect successful employment of Big Data is GIS and manipulation with environmental data sets.
Preventive archaeology, I firmly believe, will start using Big Data concepts very soon after they will be applied and tested in the academic domains. I do not predict here any radical changes in field methods and recording, much greater potential lies in manipulation with datasets from many projects. Large collections of pottery, bones etc., from dozens or even hundreds of sites or excavations, provided they are accessible online, can be analyzed regardless of the fact that they are not fully uniformly recorder or are stored on different servers. One can only imagine not only how this may assist in preparing reports from large-scale excavations, but the whole archaeological syntheses on regional or even larger scales. To reach this level there must be a serious investment in networking and Gig Data clouds. The truth is that archaeology, at the moment, is still not commercially attractive for Big Data companies to be engaged more intensively in our field, but this will not last long. 


\section{References}

Aiden, E. and Michel, J.-B. 2013. Uncharted. Big Data as a lens on Human Culture, Riverhead Books, New York.

Bozoki-Ernyey, K. 2016. Legal and Institutional Framework of Preventive Archaeology in the Past Twenty Years and Today's Reality in Hungary - a Brief Overview of the Tendencies, In: P. Novaković, M. Horňak, M. P. Guermandi, H. Stauble, P. Depaepe and J.-P- Demoule (eds.), Recent Developments in Preventive Archaeology in Europe, Znanstvena založba Filozofske fakultete Univerze v Ljubljani, Ljubljana, 233-246.

Bradley, R. 2006. Bridging the two cultures - commercial archaeology and the study of prehistoric Britain, The Antiquaries Journal 86, 1-13.

Carver, M. 1996. On archaeological value, Antiquity 70, 267, 45-56.

CIfA regulations, standards and guidelines [https://www. archaeologists.net/codes/cifa].

Convention for the Protection of the Archaeological Heritage of Europe (revised) (Valletta, 1992), [https://www.coe. int/en/web/culture-and-heritage/valletta-convention].

Czifra, S. and Fabian S. 2016. Towards a new Horizon: development-led large scale excavation policy in Hungary post-1990's, In: P. Novaković, M. Horňak, M. P. Guermandi, H. Stauble, P. Depaepe and J.-P- Demoule (eds.), Recent Developments in Preventive Archaeology in Europe, Znanstvena založba Filozofske fakultete Univerze v Ljubljani, Ljubljana, 219-231.

Demoule, J. P. 2010. The crisis - economic, ideological, and archaeological, In: N. Schlanger and K. Aitchison (eds.), Archaeology and the Global Economic Crisis, Culture Lab Editions, 13-18.

Fitzpatrick, A. 2012. Development-led archaeology in the United Kingdom: a view from AD 2010, In: R. Bradley, C. Haselgrove, M. Vander Linden and L. Webley (eds.), Development-led Archaeology in Northwest Europe, Proceedings of a Round Table at the University of Leicester $19^{\text {th }}$ $21^{\text {st }}$ November 2009, Oxbow Books, Oxford: 139-156.

Guermandi, M. P. 2016. Birth and Crib Death of Preventive Archaeology in Italy, In: P. Novaković, M. Horňak, M. P. Guermandi, H. Stauble, P. Depaepe and J.-P- Demoule (eds.), Recent Developments in Preventive Archaeology in Europe, Znanstvena založba Filozofske fakultete Univerze v Ljubljani, Ljubljana, 301-312.

Harwitz, J., Nugent, A., Halper, F. and Kaufman, M. 2013. Big Data for Dummies, John Willey and Sons, Hoboken, New Jersey.
Măgureanu, A. and Măgureanu, D. 2016. Preventive Archaeology in Romania Between Negotiation and Myth: some thoughts, In: P. Novaković, M. Horňak, M. P. Guermandi, H. Stauble, P. Depaepe and J.-P- Demoule (eds.), Recent Developments in Preventive Archaeology in Europe, Znanstvena založba Filozofske fakultete Univerze v Ljubljani, Ljubljana, 257-270.

Mayer-Schönberg, V. and Cukier, K. 2013. Big Data. A revolution That Will transform How We Live, Work, and Think, An Kamon Dolan Book/Houghton Mifflin Harcourt, Boston, New York.

Novaković, P., Grosman D., Masaryk, R and Novšak, M. 2007. Minimalni standardi izkopavalne dokumentacije: pregled stanja in predlogi standardov, Ministrstvo za kulturo RS, hhttps://www.academia.edu/16558358/Minimalni_standardi_izkopavalne_dokumentacije_pregled_ stanja_in_predlogi_standardov].

Everill P. 2009. The Invisible Diggers. A study of British Commercial archaeology, Oxbow books, Oxford.

Novšak, M. 2016. Working in Preventive Archaeology in Slovenia: A View from the Trenches, In: P. Novaković, M. Horňak, M. P. Guermandi, H. Stauble, P. Depaepe and J.P- Demoule (eds.), Recent Developments in Preventive Archaeology in Europe, Znanstvena založba Filozofske fakultete Univerze v Ljubljani, Ljubljana, 153-159.

Pravilnik o arheoloških raziskavah, 2013. Uradni list RS $3 / 13$.

Rajkovača, T. 2017. Frameworks and Development Perspectives of Preventive Archaeology in Bosnia and Herzegovina and Serbia, PhD thesis, University of Ljubljana.

Simion, M. 2016. Motorways and Archaeology: What does it mean to be a contractual archaeologist in Romania?, In: P. Novaković, M. Horňak, M. P. Guermandi, H. Stauble, P. Depaepe and J.-P- Demoule (eds.), Recent Developments in Preventive Archaeology in Europe, Znanstvena založba Filozofske fakultete Univerze v Ljubljani, Ljubljana, 271280.

Willems, W. J. 2009. Archaeological resource management and academic archaeology in Europe. Some observations, In: A. L. D'Agata (ed.), Quale futuro per l'archeologia, Workshop Internazionale, Roma, 4-5 Decembre 2008, Gangemi Editore, Roma, 89-99.

Willems, W. J. H. and Brandt, R. W. 2004. Dutch Archaeology Quality Standard, Den Haag, [https://downloads. arqueo-ecuatoriana.ec/ayhpwxgv/estandares/ArqueoHolandia.pdf]. 